\title{
Capabilities as causal powers
}

\author{
Nuno Martins*
}

\begin{abstract}
The author argues that Sen's capability approach is primarily a philosophical under-labouring exercise aimed at elaborating certain central economic categories, and that the philosophical and methodological underpinnings of Sen's approach are radically different from those of contemporary welfare economics and mainstream economic practice. Sen's notion of 'capabilities' as the potential functionings to achieve well-being is interpreted here as a specification of the ontological category of 'causal power', presupposing an open system conception of reality that contrasts with much of contemporary economic practice.
\end{abstract}

Key words: Capabilities, Powers, Structures, Ontology

FEL classification: B41, D63, I31, Z13

\section{Introduction}

Amartya Sen's capability approach has often been accused of being 'too vague' (most prominently by Martha Nussbaum, 2003), or insufficiently specified. I shall argue that this criticism springs from a misunderstanding of the nature of Sen's contribution. It is as a philosophical under-labouring exercise, a project concerned with preparing the ground for science, not as a substantive theory, that the capability approach is best understood. If this thesis is correct, one should not accuse Sen of leaving the capability approach underspecified: for if Sen's contribution is mostly concerned with philosophically underlabouring socio-economic categories and concepts, it is only natural that more substantive and specific issues will be left aside.

Tony Lawson (2002) quotes John Locke (1985 [1690]) in order to describe the motivation for the under-labouring conception of philosophy:

The commonwealth of learning is not at this time without master-builders, whose mighty designs, in advancing the sciences, will leave lasting monuments to the admiration of posterity; but everyone must not hope to be a Boyle or a Sydenham; and in an age that produces such masters as the great Huygenious and the incomparable Mr. Newton, with some others of that strain, it is ambition enough to be employed as the under-labourer in clearing the ground a little, and removing some of the rubbish that lies in the way to knowledge. (Locke, 1947 [1690], pp. xlii, xliii, cited in Lawson, 2002)

Manuscript received 17 October 2004; final version received 16 December 2005.

Address for correspondence: Portuguese Catholic University, Faculty of Economics and Management, Rua Diogo Botelho, 132741690-005 Porto, Portugal; email: nmartins@porto.ucp.pt

* Portuguese Catholic University. The author acknowledges financial support from the FCT-Fundação para a Ciência e a Tecnologia. For extremely valuable comments I am most thankful to the participants of the Cambridge Realist Workshop, and to the members of the Cambridge Social Ontology Group. I should also like to thank the participants of the 2005 HDCA conference and the Research Seminars of the Faculty of Economics and Management of the Portuguese Catholic University, Porto. I should also like to express my gratitude to Mário da Graça Moura, John Latsis and two anonymous referees.

(C) The Author 2006. Published by Oxford University Press on behalf of the Cambridge Political Economy Society. All rights reserved. 
Lawson identifies three approaches to philosophical under-labouring: demystifying inconsistencies, unreflected-upon assumptions and confusions in any knowledge activity (such as science, common-sense or everyday thinking); informing scientists of the nature of contributions to knowledge (in the discipline and across disciplines); and methodfacilitating functions, by clarifying the conditions under which given methods are appropriate. Lawson also argues that philosophical under-labouring has been a central part of the project of critical realism in economics (on which see Lawson, 1997, 2003) where much effort has gone into investigating and clarifying concepts as well as the underlying assumptions of economic theory.

My thesis, to repeat, is that Sen's critique of mainstream welfare economics and mainstream economic theory can also be seen as a philosophical under-labouring exercise of a similar sort. Sen's contribution is essentially concerned with providing the ground for economic science, rather than with substantive analysis per se. One of the most significant aspects of Sen's work is the clarification of social categories such as rationality, choice, agency, advantage, freedoms, potentialities and capabilities from a philosophical point of view, opening up new perspectives for economic analysis.

Now, even though I want to argue that Sen's contribution is essentially a philosophical under-labouring exercise, it is also true that Sen does not engage in explicit ontological analysis at the same level of abstraction as, for example, critical realism in economics. For even though Sen philosophically under-labours such categories as capability and functioning, among others, the more general ontological properties of the latter features are often left implicit in the discussion, and not elaborated. I shall suggest that it is useful to draw upon an explicitly socio-ontological perspective, in order to systematise the more general ontological commitments of Sen's approach.

To undertake such a task, I shall resort to Tony Lawson's conception of social ontology. I do so because I regard it as the best (defended) account of social ontology available. Here, I shall not repeat its various defences (on this, see Lawson, 1997, 2003, or Fleetwood, 1999), but use its results as a resource. Furthermore, adopting this strategy is advantageous because while other authors who undertake ontological analysis are concerned with science in general, Lawson's approach is focused on economics and the social realm in particular. Thus Lawson's analysis can be easily used to address Sen's work, for both are mainly concerned with the same field of enquiry.

In addition to the argument that Sen's capability approach is essentially a philosophical under-labouring exercise, in which Sen elaborates categories such as capability, functioning, advantage and well-being, I shall also discuss the more general ontological commitments of the capability approach which are left implicit in Sen's discussion. Specifically, I shall argue that Sen's emphasis on capabilities and potentials can be fruitfully interpreted as part of an ontology of 'causal powers'. I elaborate upon the notion of causal powers, and will argue that Sen's notion of 'capabilities' is best interpreted as a particular specification of the ontological category of 'causal power'.

The ethical implications of the capability approach have received much attention, since the capability approach was introduced within the context of ethical analysis. But the capability approach also has an ontological role, and points to a conception of causal powers. In Section 1, I provide a brief sketch of Sen's capability approach and, in Section 2, I argue that the capability approach is essentially an ontological exercise. In Section 3, I discuss the various levels of abstraction that an ontological exercise can have, and suggest Tony Lawson's social ontology as an ontological exercise which can fruitfully complement Sen's analysis, for the two projects operate at different levels of abstraction. 
In Section 4, I describe Lawson's structured ontology and, in Section 5, I argue that Sen's capability approach is underpinned by an ontology of causal powers in line with Lawson's structured ontology, and that Sen's approach leads to an open system conception of reality. In Section 6, I explain why the suggested interpretation of the capability approach bears the implication that the philosophical and methodological underpinnings of the capability approach are significantly different from those of contemporary mainstream economics.

In Section 7, I argue that this open system conception of reality is also present in Sen's writings on rationality and choice while, in Section 8, I argue that: (i) Sen's view of development processes is underpinned by a conception of reality similar to Lawson's; (ii) interpreting Sen's capability approach in the light of Lawson's structured ontology shows that structural transformation is the means to capability enlargement; (iii) Sen's and Lawson's perspective are to a great extent complementary, for both are concerned essentially with philosophical under-labouring, though working at different levels of abstraction.

\section{The capability approach}

In his capability approach, Sen argues that the appropriate space to assess well-being is not utility or goods or commodities or even resources. While the latter are only a means to well-being, the former (i.e., utility), in any of its various interpretations (happiness, desire satisfaction or actual choice) reflects a subjective mental metric which does not capture real welfare or deprivation (for example, because the subjective preferences of a person might become adapted to a worse situation). Rather, well-being must be analysed in the space of human functionings. These human functionings are the person's actual achievements, that is, what a person is or does.

Sen distinguishes well-being and advantage as two distinct concepts. While well-being refers to actual achievement, advantage refers to potential achievement. So the appropriate space in which to judge human advantage and inequality is not that of actual (achieved) functionings - for these only reflect well-being -but rather the space of potential functionings. Sen names this set of potential functionings as 'capabilities'. Capabilities are thus potentials, which can be actualised, and well-being will depend on the particular functionings that are actualised (that a person achieves).

Sen's view that human advantage and equality should be assessed in the space of potential well-being is a perspective that contrasts with the focus on actual utilities or resources that pervades mainstream welfare economics. Against this perspective, Sen (1999B, 2002) has consistently placed freedom to achieve (capability) as the central category of his analysis.

Now, it is important to note that Sen's conception of freedom is not exhausted by the notion of negative freedom, i.e., freedom from constraints. Sen also stresses that freedom is important as freedom to be and to do. Sen's conception of freedom is one where the capability or power to achieve must be a real possibility. Sen argues that even 'valuating negative freedom must have some positive implication' (Sen, 1984, p. 313), and hence advocates that a correct conception of freedom cannot disregard the positive aspect of freedom. Sen writes:

I have found it more useful to see 'positive freedom' as the person's ability to do the things in question taking everything into account (including external restraints as well as internal limitations) ... This way of seeing positive freedom is not the one preferred by [Isaiah] Berlin, but it is close to the characterisation presented by T.H. Green: 'We do not mean merely freedom from restraint or compulsion ... When we speak of freedom as something so highly prized, we mean a positive power or capacity of doing or enjoying something worth doing or enjoying'. (Sen, 2002, pp. $586-7$, emphasis in original) 


\section{N. Martins}

The aim of Sen with his capability approach is to elaborate upon a conception where the emphasis is on real and positive powers, capacities and capabilities as potentials, rather than actualities.

Now, I shall argue that, in advancing these concepts, Sen is effectively undertaking a philosophical under-labouring exercise, in which ontological categories are elaborated. In the next section I shall further explain this claim.

\section{Ontology and philosophical under-labouring}

I shall start by clarifying my terms. By 'ontology' I mean an enquiry into the nature of being. Social ontology is a concern with social being, where the latter refers to the part of reality whose existence depends at least in part upon us (see Lawson, 1997, 2003). This enquiry can be undertaken in order to understand the nature of specific social entities or, at a more abstract level, to determine the general properties of these entities and of social reality.

An example may be useful to understand the distinction between ontology and scientific theories. A positive correlation between money supply and the level of prices constitutes an empirical observation. A scientific theory would be a theory that would explain such an empirical observation: for example, a theory about a causal mechanism or structure through which a higher level of money supply causes a higher level of prices. But ontological analysis is aimed not at analysing how a specific mechanism or structure causes actual events, but rather at understanding the nature of the entities posited in scientific theories. For example, an enquiry aimed at understanding the nature of money - and not an explanation of a specific causal mechanism through which money influences priceswould be deemed ontological.

Of course, an ontological analysis of the nature of money (or of any entity) would certainly include an analysis of its properties (for example causal properties), which in turn play a role in the scientific theories about money. Ontological analysis and scientific theories are strongly interrelated: scientific theories draw upon the entities analysed at an ontological level, and the successes or failures of scientific theories are extremely important to assess the validity of the ontological presuppositions of scientific theories. But ontology and science are two different, even though interrelated, exercises. Ontology is a study of the nature of reality, including the entities presupposed by scientists and the properties of such entities at a more general level, while science analyses more specific causal structures and mechanisms and the manner in which actual events are brought about.

With this in mind, one can see why Sen's capability approach is an ontological exercise. The capability approach is not aimed at understanding specific causal mechanisms through which human advantage and well-being can be fostered. Rather, the fundamental concerns of Sen's capability approach are questions such as 'what is advantage' or 'what is well-being'. Sen's main goal is to elaborate such categories as 'well-being', 'advantage', 'development', 'capabilities' and 'functionings', among others, in order to understand what they mean, and to determine their general causal properties (not to develop a scientific theory about specific causal mechanisms that can be posited using these categories).

Sen's aim is to under-labour philosophically for science (by elaborating upon social categories to be used in specific theories), not to do science (to develop specific scientific theories). It is widely recognised that Sen's capability approach is not a specific social theory. In fact, Sen's capability approach has often been accused of not being specific enough (see, for example, Nussbaum, 2003). But the ontological nature of Sen's contribution has received little (if any) attention. Rather, the capability approach has 
been interpreted as being only an ethical theory. Hilary Putnam (2002), for example, argues that Sen's perspective is concerned with bringing ethics back to economics, while taking ethics to exclude any concern with ontology (see also Putnam, 2004).

The capability approach can indeed be fruitfully used for ethical analysis. In fact, it is aimed at providing a space for the assessment of equality. But this is achieved by means of an ontological exercise, and not through ethical theorising. The context in which the capability approach was introduced was an ethical debate, in which Sen criticised neoclassical welfare economics on the one hand, and the Rawlsian emphasis on primary goods on the other. But the main contribution of the capability approach was to provide an informational basis to assess inequality, not to provide an ethical theory or a theory of justice, as Sen notes.

The theories Sen criticised when introducing the capability approach were ethical theories. Rawls, for example, not only suggested the space of primary goods, as he also chose a prescriptive criterion to combine with such a space-the maximin criterion. For Rawls, the prescriptive question of 'what should be done' was a crucial one, hence the need to provide the prescriptive criterion that the level of primary goods to be maximised was the level of primary goods of the worst-off individual (the maximin criterion). But Sen, unlike Rawls, did not provide a prescriptive criterion in his capability approach. In Sen's capability approach, the important question was not the prescriptive question of 'what should be done', but rather ontological questions ('what is advantage and well-being', etc.).

Sen's aim was to provide descriptions of the concepts under analysis. These can of course be used for ethical theorising and for more substantive analysis. Ontological description and ethical prescription can be mutually enriching and complementary. One must distinguish between a vision of ethics without ontology, where the exclusive concern is with prescriptive criteria, and an integrated view of ethics and ontology, where evaluation is much concerned with the description of categories such as 'well-being', 'advantage', 'functionings' and 'capabilities' from an ontological point of view. Nevertheless, ontological description and ethical prescription are still different exercises, and Sen's capability approach is concerned with the former, not with the latter.

\section{Ontology and the level of abstraction}

Now, as it was said before, ontology can be aimed at analysing which entities constitute social being or, at a more abstract level, which are the general properties of those entities and of social reality. The former analysis is termed scientific ontology by Lawson (2005), for it is typically concerned with the entities posited by scientific theories (even though it can be extended to cover entities other than those posited by scientific theories). The latter is distinguished as philosophical ontology, for it is concerned with the properties of entities at a philosophical or more general level. Sen's capability approach can be seen as a contribution to scientific ontology, to the extent that it scrutinises entities such as 'wellbeing', 'advantage', 'functioning' or 'capability', among others. In contrast, explicitly philosophical-ontological contributions typically go to a higher degree of abstraction, engaging in the analysis not only of the entities that constitute social being, but also of the more general properties of social being.

One example of contributions to philosophical ontology (that is, undertaken at the above-mentioned higher level of abstraction) can be found in the work of Lawson (1997, 2003), and in several contributions to the economic literature systematised under the heading of critical realism in economics. In these contributions, while the ontological 
analysis of more substantive social categories such as 'money', 'institution' or 'development' is surely an important part, the main emphasis (at least so far) has been on the more general properties of social being: for example, properties such as structure, causality, interconnectivity, openness/closure, among others. In the work of Lawson, for example, the social realm is characterised as being structured, interconnected (that is, its constituents are highly relational), emergent, dynamic and open.

Sen's capability approach is not concerned with this level of abstraction; and Lawson does not provide an ontological analysis of more substantive entities such as 'functioning' and 'capability'. In the same way that ontology and scientific theories differ in the level of abstraction (the latter is concerned with how specific mechanisms cause actual events, and the former is concerned with the nature of the entities posited in science), even within ontological analysis, there can be lower levels of abstraction (for example, Sen's characterisation of more concrete entities such as 'functioning' and 'capability') and higher levels of abstraction (for example, Lawson's description of such general properties of the social realm as structure, interconnectivity, openness, among others). This is captured by Lawson's (2005) distinction between scientific and philosophical ontology.

Nevertheless, the analysis of entities such as 'functionings' and 'capabilities' implies some conception of the properties that such entities possess. When discussing the nature of a functioning and of a capability, Sen makes some implicit presuppositions about whether a process of human development (characterised in terms of the expansion of the person's capabilities) is structured or not, interconnected or atomistic, open or closed, and so forth. In order to understand these ontological commitments that Sen makes, I draw upon the social (philosophical) ontology of Tony Lawson.

In fact, Sen's and Lawson's approaches can be seen as complementary, for they are undertaken at different levels of abstraction, i.e., scientific ontology and philosophical ontology, respectively. So far, my main claim was that Sen's capability approach is an exercise in scientific ontology, aimed at describing categories such as well-being, potential well-being, functionings, capabilities and development, among others. The second claim to be made now will be that, while Sen does not explicitly elaborate upon the more general properties of these categories (at the level of philosophical ontology), he has nevertheless an implicit conception of these properties, which is similar to the critical realist one. I shall turn to this second claim now. I shall start by providing a sketch of Lawson's social ontology.

\section{Powers, structures and open systems}

According to Lawson's $(1997,2003)$ structured ontology, reality is constituted by structures, powers, mechanisms and tendencies, in addition to actual events and states of affairs, and their perception and impression. Structures are the underlying conditions of possibility that enable or facilitate the occurrence of a given phenomenon. Structures comprise powers that may or may not be exercised and, when exercised, may or may not be actualised in actual events and states of affairs. Mechanisms refer to the mode of operation of structures and exist as the power that a structure possesses of acting in a given way. This operation of mechanisms, when exercised, triggers forces into motion, which Lawson names tendencies. The term 'tendency' is meant to capture the idea of a continuous activity that may or may not be actualised in concrete events and states of affairs, even when it is continuously exercised. 
These structures, powers, mechanisms and tendencies constitute the underlying causes of observed events. From this perspective, to view causality as a constant conjunction between events does not give an adequate account of reality. The aim of science should rather be to understand which structures, powers, mechanisms and tendencies are responsible for specific events.

It is important to note that both generative mechanisms and tendencies are themselves causal powers of a structure: mechanisms exist as the power that a structure possesses to act in a given way, while a tendency occurs as a causal power is (or many causal powers are) continuously exercised. For this reason, I shall often refer to structures and causal powers only, adopting a broad conception of the latter that encompasses mechanisms and tendencies as well.

Notice that the claim that observable events are caused by underlying structures, causal powers and tendencies does not mean that the latter can be directly read off from experience. Rather, this is a transfactual claim about causal powers that can be exercised whatever events are observed: a claim about the operation of structures and causal powers, regardless of whether this operation necessarily produces observable (actual) event regularities.

Let me refer now to the distinction between closed systems and open systems. According to Lawson, closed systems are systems in which constant conjunctions of the form 'whenever event $X$ then event $Y$ ' occur. Systems in which these constant conjunctions do not always occur are open systems. In Lawson's perspective, science is concerned with the causal powers, capacities and dispositions that objects possess. These causal powers may or may not be exercised, and when exercised, may or may not be actualised. Unless these causal powers always manifest themselves in a constant, isolated or predictable way, the reality under analysis will constitute an open system, (see Lawson, 1997, 2003).

In Lawson's conception, as we have seen, powers or capacities are explained in terms of underlying structures. Structures can be physical, biological, psychological or social structures. In Lawson's ontology, social structures are constituted by social rules, which are attached to given social positions. And social positions are internally related. As Lawson explains, '[a] spects or items are said to be internally related when they are what they are, or can do what they do, by virtue of the relations in which they stand' (Lawson, 2003, p. 17). When parts of a given phenomenon are internally related, these parts in isolation will not possess the essential properties of the whole. These (internally related) social positions (that are attached to given social rules) constitute the underlying social structure that facilitates or constrains human agency and social practices.

Another important concept to be introduced at this stage is that of emergence. Lawson explains that ' $[\mathrm{e}]$ mergence may be defined as a relationship between two features or aspects such that one arises out of the other and yet, while perhaps being capable of reacting back on it, remains causally and taxonomically irreducible to it' (Lawson, 1997, p. 63). It can be the case that objects are interrelated in a structure in such a way that higher level properties, which can be powers or potentials, arise out of the lower level activity, but nevertheless nothing in the lower level activity could enable the prediction of such higher level properties.

When the object of our analysis is structured in such a complex way as described above (including internal relations and emergence), the causal powers that arise out of this structure will typically entail an open system conception of reality, for these causal powers will most likely not be manifest in a constant, isolated or even predictable way. 


\section{Capabilities and open systems}

Capabilities, like causal powers in general, are not actualities-they are potentials that may or may not be exercised and/or actualised. And similarly to causal powers, capabilities arise by virtue of underlying physical, biological, psychological or social structures which facilitate or constrain a particular achievement or functioning. Furthermore, the set of functionings that are actually achieved by a person is the actualisation of a power (or potential).

Now, I want to argue that Sen's capability approach not only allows for an open system conception of reality, as it effectively suggests such a conception. It is easy to see why Sen's emphasis on capabilities as potentials allows for an open system conception of reality. Potentials may or may not be exercised and/or actualised in a permanent way and, even when exercised and actualised, they need not deliver the constant regularities that are typical of a closed system.

Of course, one may wonder why causal powers, capabilities and potentials will necessarily lead to an open system conception or reality. In fact, it does not necessarily follow that they will entail an open system conception of reality-powers, capabilities or any sort of potentials may be permanently actualised in stable event regularities. One can argue, for example, that, at least in some situations, the causal powers of an object may be relatively constant, or not manifest, or insufficiently isolated to be identified (without experimental control). If, however, capabilities, potentials, powers or capacities can be permanently actualised in event regularities (or never actualised at all), thus generating a closed system, why must Sen's capability approach lead to an open system conception of reality?

The point to note is that Sen's emphasis on capabilities and functionings makes sense only in the context of an open system. And this is so because capabilities, potentials, powers or capacities would be irrelevant for any analysis if they were always actualised in a closed system, or if they were never actualised at all. Notions such as capability, potential, power or capacity are relevant only if they may or may not be actualised in different circumstances, in an open system.

If capabilities, causal powers or potentials, were never actualised, it is obvious that they would be irrelevant for our analysis. If, on the other hand, capabilities, causal powers or potentials were permanently actualised as a constant conjunction of events (a possibility that can never be excluded a priori) — and thus closed systems would be ubiquitous - then the very notion of potential, power or capacity would become superfluous to scientific explanation. If causal powers were permanently exercised as a constant conjunction of events, it would be enough for science to undertake correlation analysis in order to obtain regularities between those events. It is only the fact that causal powers may or may not be exercised, and when exercised may or may not be actualised, within the context of an open system that makes these concepts important and necessary to scientific explanation.

Moreover, note that if capabilities and causal powers were permanently actualised in event regularities within a closed system, there would be little, if any, scope to discriminate and identify the underlying powers, potentials or capacities that were causing the observed event regularities. Causal powers are identified just when contrasting situations are observed, where the fact that different powers may or may not be actualised enables scientists to discriminate and identify them. But if powers are permanently actualised in event regularities, they become indistinguishable from the event regularities they generate, and thus superfluous for our analysis - for the corresponding event regularities would suffice as an account of causality. 
So if the capability approach, or any approach that suggests the analysis of potentials (or causal powers), is to be of any relevance, it must presuppose an open system conception of reality. Otherwise (i.e., under a closed system conception of reality), analysis of actual regularities (and achieved welfare) would suffice, rendering the very concept of capability as potential functioning superfluous.

Furthermore, as will be argued later on, a scrutiny of Sen's contributions in various areas - such as his writings on rationality and on development processes-shows that this open systems (and causal powers) view underpins other aspects of Sen's work as well, and reinforces this point. Throughout his contributions, Sen's emphasis has always been on the centrality of freedom to understand human agency and advantage. I shall return to this point in the next three sections.

\section{The methodology of modern mainstream economics}

Sen's perspective has been criticised on the grounds that it does not really go beyond the traditional mainstream approach to economics. Bernard Guerrien, for example, argues that 'Amartya Sen, as an economist, is a standard microeconomist (that is what he was awarded the Nobel Prize for): only the vocabulary is different ("capabilities", "functionings", etc.)' (Guerrien, 2002).

Emmanuelle Benicourt, in a similar vein, writes

when Sen explicitly describes his system (particularly in Commodities and Capabilities, 1985), it becomes clear that it is just a variation of the mainstream approach. Instead of reasoning in terms of an n-dimensional space composed of 'commodities' (goods or utilities), Sen proposes a space of 'functionings'. (Benicourt, 2002)

The question one might ask, then, is whether Sen's emphasis on 'powers' and 'capabilities' as 'potential functionings' brings something that is not provided by the mainstream approach to economics. Do these concepts refer to something that is substantially different from the usual categories of the mainstream approach? I shall argue that Sen's capability approach is actually very different from the mainstream approach. Sen's shift to a space of potentials, powers and capacities ultimately implies radically different philosophical and methodological underpinnings for economic analysis.

Modern mainstream economic practice is committed to a methodology that, unlike Sen's capability approach, is inconsistent with open systems. To the contrary, the use of methods that presuppose closed systems is one of the central features of modern mainstream economics. In fact, Lawson $(1997,2003)$ has argued that the essence of modern mainstream economics is an insistence on methods of mathematical-deductivist modelling, which in turn presuppose closed systems.

Deductivism is defined by Lawson (2003, p. 5) as 'a type of explanation in which regularities of the form "whenever event $x$ then event $y$ " (or stochastic near equivalents) are a necessary condition'. So deductive models presuppose the existence of closed systems: for closed systems are precisely defined as those in which to each possible event $X$, another event $Y$ will correspond.

Notice that mainstream economists are often open to competing theories of economic phenomena. In fact, mainstream economists sometimes claim to have a view of the world which can be argued to be similar to the critical realist one, where the aim is to find underlying structures, not empirical correlations (see, for example, Samuelson, 1963). Nevertheless, this claim is conjoined with the requirement that all analysis of economic 
phenomena (grounded on whatever theory) must be undertaken using a deductive methodology.

Notice, moreover, that one could argue that the presumption of many mainstream economists is not that exact regularities are displayed in a straightforward way in reality. One could argue that their view is rather that whatever complexity reality has, it can ultimately be understood using deductive models. Furthermore, the use of these methods, which presuppose exact event regularities, is often argued (by mainstream economists) to be an advantage of this mainstream approach over other economic (and sociological) traditions.

It must be conceded that the possibility of explaining some particular reality using methods that presuppose closed systems cannot be excluded a priori. The validity of a deductive methodology can only be refuted after it is inferred a posteriori that the conditions of possibility of some generalised features of experience are inconsistent with deductive methods (because a closed system does not obtain).

In an open system, however, exact event regularities must be generated by means of experimental control (as is the case in natural sciences). Otherwise, deductive methods will severely constrain any explanatory procedure aimed at analysing an open system, where powers, capacities and potentials do not permanently manifest themselves in a constant and predictable way.

The point I should like to stress at this stage is not that social reality is an open system (although I believe it is; on this, see Lawson, 1997, 2003). What I want to emphasise is that, rightly or wrongly, modern mainstream economics (including mainstream welfare economics) relies on a methodology that is inconsistent with open systems.

Once this is recognised, one can see why Sen's capability approach is a perspective the philosophical and methodological underpinnings of which are radically different from those of mainstream economic practice. In fact, if one interprets Sen's notions of 'primary powers' (Sen, 1984) and 'capabilities as potentials functionings' as a specification of the ontological notion of 'causal powers', where these allow for, and their analysis and elaboration takes for granted, an open systems conception of reality, one can see how this is a perspective whose implications are very significant not only for welfare economics, but for economics in general. Since most mainstream economic practice is underpinned by a methodology that is inconsistent with open systems, Sen's approach is not just the 'capability approach to welfare economics', but the capability (or causal powers) approach to economics as a science, an approach where the emphasis is on potentiality, freedom and openness.

\section{Rationality and open systems}

The extension of this open systems conception to fields other than welfare economics is implicitly present even in Sen's own work-for Sen's critique of mainstream economics has arisen in contexts other than welfare economics. Sen has also criticised standard rational choice theory and (micro)economic theory as an account of human action and choice. Sen argues against the two dominant perspectives on rational behaviour, which he describes as the 'self-interest pursuit' approach and the 'internal consistency' approach.

In the former approach, human choice is always explained as a pursuit of self-interested goals (which are represented by a complete preference ordering). Sen shows how this approach omits many important determinants of human choice other than self-interest, such as social rules, moral imperatives, moral sentiments, conventional rule following or 
social commitment (see Sen, 1997), and he also argues that the joint outcome of these complex reasons for choice need neither conform to the posited self-interested preference ordering of the agent nor even deliver exact regularities of observed behaviour.

In the 'internal consistency' approach, on the other hand, every choice is again explained in terms of an underlying complete preference ordering (as in the 'self-interest pursuit' approach), but now this preference ordering is 'revealed' in choice (instead of simply posited initially as a representation of the self-interest of the human agent), and so is inferred from observed behaviour. Sen criticises this approach on the grounds that conditions of internal consistency do not typically occur in human behaviour, i.e., exact regularities of actual behaviour do not typically obtain.

Sen notes how both these approaches (i.e., the 'self-interest pursuit' approach, and the 'internal consistency' approach) ultimately aim at obtaining an account of rational behaviour that enables prediction of actual behaviour. This is achieved by: first describing rational behaviour in an exact and predictable way (for example, according to a complete preference ordering of competing options); and, second, supposing that rational behaviour coincides with (or at least approximates) actual behaviour (Sen also notes how these approaches are often conflated, for the binary relation of revealed preference is often defined as the binary relation of self-interested preferences).

Sen has criticised the mainstream view that rational choice theory and economic theory should aim at prediction of actual behaviour (see Sen, 1982, 1987, 1997, 2002; also Meeks, 1991), arguing also against the assumption that human agents permanently behave according to some complete and exact preference ordering. In fact, Sen (2002) proposes an alternative conception of rationality, according to which the term means the discipline (and the need) of engaging in reasoned scrutiny of goals and values at any time (even though this discipline is not permanently exercised). Sen (1997) even argues that preference orderings are very often incomplete, i.e., there can be two options A and B such that the human agent neither prefers one to the other, nor is indifferent between them. Rather, these two options are not ranked in any way vis-à-vis each other, and the choice made by the human agent can be any of them.

This is a view that contrasts with the mainstream account of choice as the outcome of optimising behaviour according to complete preferences. The conception of human behaviour of mainstream microeconomic theory is certainly in line with a closed systems conception, for behaviour is determined by a completely specified (and permanently exercised) preference ordering. But in Sen's account of rationality there is no need for this regularity of behaviour, and human behaviour does not necessarily conform to any sort of closed system for: preference orderings are incomplete, and rationality does not even mean to conform to any preference ordering. Rather, Sen's view presupposes that human agents always have the freedom, capability or power to choose differently than they did (where this freedom, capability or power will of course be facilitated or constrained by the underlying biological and/or social structures upon which the former depend).

This conception of rationality and choice that Sen puts forward, if correct, makes it clear that human behaviour need not conform to constant or predictable regularities, and hence the relevant situation will be that of an open system.

\section{Causal powers, structural transformation and interconnectedness}

So far, it has been argued how Sen's perspective, of judging human advantage in terms of their potentials, powers or capabilities (and not in terms of actual well-being), can be 


\section{N. Martins}

fruitfully linked to the described (socio)ontology of causal powers, whose philosophical and methodological underpinnings are radically different from those presupposed by the methodology of modern mainstream economics. In what follows, I shall try to draw the policy implications of interpreting Sen's notion of capabilities as causal powers in the context of Lawson's structured ontology. Lawson writes

on the critical realist understanding a feasible aim is to transform real social structures in order to facilitate alternative opportunities. There thus arises the possibility of enhancing the scope for human potentials to be realised, of broadening human opportunities; it is feasible to think in terms of replacing structures that are unwanted, unneeded and restrictive by those that are wanted, needed and empowering. Choice is no longer denied. On the contrary, it lies within the realms of policy objectives to aim to widen the scope of choice, with respect, in particular, to options that are both needed and desired. (Lawson, 1997, p. 277)

Sen's capability approach has many similarities with this critical realist perspective on social emancipation: for both suggest undertaking ethical analysis in a space of human potentials. But notice that the critical realist point that powers, potentials and capacities arise in virtue of the way that reality is structured, implies that the means to broaden human potentials, powers and capacities is structural transformation, as Lawson points out.

This is an important aspect where Lawson's structured ontology and Sen's capability approach can complement each other. If the capability approach points to an ontology of powers, potentials and capacities, and if in the critical realist structured ontology these powers, potentials and capacities arise in virtue of underlying structures, then an understanding of these structures seems to be crucial if we want to broaden human capabilities and potential functionings.

Conversely, notice that Sen's specification of the category of powers as 'capabilities' can also help critical realists to address the more concrete and empirical issues that Sen discusses, such as poverty, development processes and income distribution. Even if the main emphasis of Sen's analysis has been on a philosophical under-labouring role, it is clear that some of his work has also focused on more concrete issues, such as the empirical analysis of poverty, income distribution and development processes. On the other hand, other projects that engage in philosophical under-labouring, such as critical realism in economics, have been much more concerned with explicit and systematic ontological analysis, not with empirical analysis per se. Furthermore, remember that, even where philosophical under-labouring is concerned, both approaches have worked at different levels of abstraction. Sen has been preoccupied with clarifying social categories at a less abstract level (categories such as 'well-being' and 'advantage'), at the level of scientific ontology, while critical realism has addressed more general properties of the social realm such as structure, openness/closure, internal relations, emergence and many others, at the level of philosophical ontology. So both approaches are complementary and mutually enriching.

While Sen's analysis can help critical realists in applying their ontological analysis of structures and powers to concrete issues, the critical realist explanation of social structures, as comprising social rules attached to each social position (where these social positions are internally related), can provide ontological insight into how powers and capacities can be broadened. The suggestion of structural transformation, in order to broaden human capacities and potentials, comes from the ontological insight that capacities, powers and potentials arise by virtue of the way reality is structured. But to understand the way in which these (internally related) structures are reproduced and/or transformed through human agency (in a context of open systems) also requires empirical analysis. 
Notice that this open system conception of a structured, interconnected (and internally related) reality is also implicitly present in Sen's own analysis of development processes. The fact that Sen's work (including his ontological description of the nature of well-being, advantage, functionings and capabilities) is situated at a more concrete level than critical realism in economics does not mean that his analysis is not underpinned by implicit ontological commitments at a more general level. In fact, in his account of development as freedom, Sen (1999B) argues that development must be seen within the context of the complex interconnections between (instrumental) freedoms such as 'political freedoms', 'economic facilities', 'social opportunities', 'transparency guarantees' and 'protective security' (Sen, 1999B, p. 38) - and takes these interconnections to be a central part of his argument, for these factors cannot be analysed as if they were isolated from each other. Effectively, this more general view of capabilities as causal powers is in line with Sen's argument that ' $[t]$ he capability perspective involves, to some extent, a return to an integrated approach to economic and social development championed particularly by Adam Smith' (Sen, 1999B, p. 294).

Note also that to interpret capabilities as a specification of the ontological category of causal powers not only leads us to (or at least allows for) an open systems view of reality (an aspect that also becomes very clear in Sen's account of freedom, rationality, and interconnectivity within development processes) but clarifies the role of capabilities as a 'means to' (as opposed to being just the 'end of') development. Sen writes:

In looking for a fuller understanding of the role of human capabilities, we have to take note of: 1) their direct relevance to the well-being and freedom of people; 2) their indirect role through influencing social change; and 3) their indirect role through influencing economic production. The relevance of the capability perspective incorporates each of these contributions. In contrast, in the standard literature human capital is seen primarily in terms of the third of the three roles. (Sen, 1999B, pp. 296-97)

Sen notes how freedom should be viewed as both the 'primary end' and the 'principal means' of development (Sen, 1999B, p. 36), naming these roles as the 'constitutive' and the 'instrumental' role of freedom (ibid., pp. 36-7). While much attention has been given to the ethical foundations of the capability approach (concerned with freedom as the 'primary end' of development), the ontological and methodological implications of seeing freedom as the 'principal means' of development have received relatively less attention.

Seeing capabilities as causal powers leads to a better understanding not only of Sen's other contributions, but also of the capability approach itself, by showing how freedom and capability enlargement are not only the ends of development, but also the means. The capability approach has proved a useful framework in welfare analysis, but as Marianne Hill notices, has not provided (at least so far) a theory of underlying causes of social processes:

although the capability approach provides a framework for the evaluation of individual and social welfare, it is not a theory of the social causes of poverty and inequality, nor of the effects of social institutions on human welfare. In fact, we can link criticisms of the capability approach to the need to take on the question of how to advance human welfare through social policy. In particular, we need to expand the capability approach to enable analysis of social institutions and processes, from the firm to the family and from the market to public policy-making. (Hill, 2003, p. 118)

The suggested interpretation of capabilities as causal powers can be a starting point for an analysis of social institutions and processes. The capability approach is essentially an ontological exercise, aimed at clarifying the meaning of categories such as well-being, 
advantage, functionings and capabilities. Once it is recognised that this approach is, at a more general level, underpinned by a structured ontology of powers and capacities, the latter can help us to understand different dimensions of human life and socio-economic phenomena (under this broad view of capabilities as causal powers). The expansion of human capabilities is the goal of social and economic policy, but capabilities are also the causal powers that enable or constrain social change and economic production, and can be explained in the context of underlying structures.

\section{Concluding remarks}

Interpreting Sen's work as philosophical under-labouring for economics through elaborating and clarifying social categories and concepts enables us to understand why substantive claims are often absent from his work. Sen's main concern is to clarify concepts such as well-being and advantage (suggesting categories such as functioning and capability for that purpose), in order to under-labour for the development of substantive theories. Nevertheless, one must also bear in mind that much of Sen's analysis (for example, his work on poverty, development and welfare) is also undertaken at a lower level of abstraction than perspectives such as critical realism in economics.

The social ontology conception that most coherently supports the notion of 'capability', and other social categories to which Sen refers, is a structured ontology of capacities, powers and potentials, in line with an open system conception of reality. Human beings must be seen 'as agents, rather than as motionless patients', endowed with powers, capacities and capabilities, since they are 'active themselves' (Sen, 1999B, p. 137). This ontological category of 'power' not only clarifies Sen's capability approach, it also helps us to understand his other work (for example, his writings on rational behaviour and on socioeconomic development processes).

This interpretation of capabilities as causal powers also clarifies why these are both means and ends of socio-economic development. They are (ethical) ends to the extent that capabilities are the informational basis (or the relevant 'space') for assessing inequalityand are, Sen argues, a more appropriate informational basis than 'primary goods', 'resources' or 'utilities'. But capabilities are also the means to development, because they are the causal powers (which arise in virtue of underlying structures) that enable change and transformation.

Sen's approach was first introduced in the context of welfare economics and political philosophy (in opposition to mainstream welfare economics and moving beyond Rawlsian political philosophy). Because of this, its ethical dimension has been much more scrutinised than its ontological and methodological underpinnings. But the contrast between Sen's approach and the mainstream approach exists not only in the context of ethical analysis and welfare economics, but more generally, and at least as strikingly, in their underlying ontological and methodological presuppositions.

\section{Bibliography}

Benicourt, E. 2002. Is Amartya Sen a post-autistic economist? post-autistic economics review, no. 15, 4 September, article 4 . http://www.btinternet.com/ pae_news/review/issue $15 . h t m$ Fleetwood, S. (ed.) 1999. Critical Realism in Economics, London, Routledge

Guerrien, B. 2002. Is there anything worth keeping in standard microeconomics, post-autistic economics review, no. 12, 15 March, article 1: http://www.btinternet.com/ pae_news/review/ issue $12 . \mathrm{htm}$ 
Hill, M. 2003. Development as empowerment, Feminist Economics, vol. 9, 117-35

Lawson, A. 1997. Economics and Reality, London, Routledge

Lawson, A. 2002. Philosophical under-labouring in the context of modern economics: on aiming at truth and usefulness in the meanest of ways, in Davis, J., Marciano, A. and Runde, J. (eds), The Elgar Companion of Economics and Philosophy, Aldershot, Edward Elgar

Lawson, A. 2003. Reorienting Economics, London, Routledge

Lawson, A. 2005. 'A Conception of Ontology', mimeo, Cambridge

Locke, J. (1985 [1690]). An essay concerning human understanding, An Abridgement Selected and Edited by Yolton, f., London and Melbourne, Dent

Meeks, J. G. T. (ed.) 1991. Thoughtful Economic Man, Cambridge, Cambridge University Press

Nussbaum, M. C. 2003. Capabilities as fundamental entitlements: Sen and social justice, Feminist Economics, vol. 9, no. 2/3, 33-60

Putnam, H. 2002. The Collapse of the Fact/Value Dichotomy and Other Essays, Cambridge, MA/ London, Harvard University Press

Putnam, H. 2004. Ethics Without Ontology, Cambridge, MA/London, Harvard University Press Samuelson, P. 1963. Problems of methodology: discussion, American Economic Review, vol. 53, 231-6

Sen, A. 1982. Choice, Welfare and Measurement. Oxford, Blackwell/Cambridge, MA, MIT Press Sen, A. 1984. Resources, Values and Development, Cambridge, MA/London, Harvard University Press

Sen, A. 1987. On Ethics and Economics, Oxford and New York, Basil Blackwell

Sen, A. 1993. Internal consistency of choice, Econometrica, vol. 61, no. 3, 495-521

Sen, A. 1997. Maximization and the act of choice, in Econometrica, vol. 65, 745-79

Sen, A. (1999A [1985]). Commodities and Capabilities, Oxford and New York, Oxford University Press

Sen, A. 1999B. Development as Freedom, Oxford, Oxford University Press

Sen, A. 2002. Rationality and Freedom, Cambridge, MA, The Belknap Press of Harvard University Press 